\begin{tabular}{|c|c|}
\hline Title & Surface Oxide Film and its Influence on the Oxygen Reduction on Pd-Co and Pt-Co PEFC Cathodes \\
\hline Author(s) & Tamura, Y uichi; Taneda, Kento; Ueda, Mikito; Ohtsuka, Toshiaki \\
\hline Citation & $\begin{array}{l}\text {, 16(2), 741-750 } \\
\text { https://doi.org/10.1149/1.2981910 }\end{array}$ \\
\hline Issue Date & 2008 \\
\hline Doc URL & http:/hdl .handle.net/2115/60229 \\
\hline Rights & $\begin{array}{l}\text { () The Electrochemical Society, Inc. 2008. All rights reserved. Except as provided under U.S. copyright law, this work } \\
\text { may not be reproduced, resold, distributed, or modified without the express permission of The Electrochemical Society } \\
\text { (ECS). The archival version of this work was published in ECS T ransactions, V olume 16, Issue 2, pp. } 741-750,2008 .\end{array}$ \\
\hline Type & article \\
\hline File Information & OhtsukaECS16(2-741).pdf \\
\hline
\end{tabular}

Instructions for use 


\title{
Surface Oxide Film and its Influence on the Oxygen Reduction on Pd-Co and Pt-Co PEFC Cathodes
}

\author{
Y. Tamura, K. Taneda, M. Ueda, and T. Ohtsuka \\ Division of Materials Science and Engineering, Graduate School of Engineering, \\ Hokkaido University, Sapporo 060-8628, Japan
}

PtCo and PdCo alloy electrodes were investigated in a $0.5 \mathrm{M}$ sulfuric acid solution by electrochemistry, ellipsometry, laser Raman scattering spectroscopy, XPS, and GD-OES. The corrosion resistibility of Pt-Co and Pd-Co alloys decreased with increase of Co addition. The increase of Co addition, however, enhanced the catalytic efficiency on the ORR. The alloy surfaces may be covered by $\mathrm{CoOOH}$ and $\mathrm{Pt}$ or $\mathrm{Pd}$ oxide $2-3 \mathrm{~nm}$ thick. At the potential of $1.2 \mathrm{~V}$ vs. $\mathrm{Ag} / \mathrm{AgCl} /$ sat. $\mathrm{KCl}$, the thickness of oxide film increased with the Co addition. The presence of the oxide film on the alloy electrodes increases the overvoltage for the ORR. The effect of the oxide thickness on the ORR was discussed.

\section{Introduction}

The improvement of the catalytic electrodes of the cathode to the smaller over-potential on the oxygen reduction reaction (ORR) has been desired to increase the electrocatalysis efficiency of PEFC. Recently, it was reported that Co-noble metal alloys had a higher efficiency for the ORR than pure Pt, and that the use of the Pt-Co alloy electrodes decreased the overpotential and allowed the more electric power to be generated. Alloying of the transition metal like $\mathrm{Co}, \mathrm{Ni}$ or $\mathrm{Cr}$ to noble metals enhances the catalytic efficiency (1-8). This effect has been explained by the change of Pt d-band electronic density due to the presence of the alloying elements $(1,2)$, or the more optimal oxygen adsorption on $\mathrm{Pt}$ atom in contact with the alloying elements $(3,4)$.

It has been reported that even for the Pt catalysts having large corrosion resistibility, the dissolution or corrosion takes place due to the strong acid atmosphere in PEFC cathodes and the change of the potential during the operation (9). Since cobalt metal has small corrosion resistibility in acid aqueous solution, it is expected that the corrosion resistibility of the Pt-Co alloy electrodes is smaller than that of pure Pt electrode. On bulk Pt alloy surfaces, it has been reported that Pt skin layer less than $1 \mathrm{~nm}$ thickness exists (1). The Pt skin layer may have higher stability than an alloy layer including Co for corrosion (10). The lower stability of Pt alloys, however, has been reported (11).

Some authors have reported that Pd alloys had a higher catalytic efficiency than that of pure Pd on the ORR (12-15), and the ORR on Pd-Co alloys proceeded via the direct route of the four-electron reduction $(12,13)$.

Pure cobalt is supposed to reveal a low corrosion resistibility in acid aqueous solution. The potential range of active dissolution of cobalt widely extends and the passivation only occurs just before the oxygen evolution. It is assumed that the passivation results from formation of $\mathrm{Co}$ (III) oxide which may be composed of $\mathrm{CoOOH}$. The formation of anodic oxide of cobalt has been reported in the borate buffer solution (16-19). The ORR potential range for PEFC cathode overlaps with the passivation potential of cobalt. It is predicted that the ORR on Pt-Co or Pd-Co takes place through the cobalt oxide film on 
the surface. Since the dissolution of cobalt is much larger than that of $\mathrm{Pt}$ or $\mathrm{Pd}$, the preferential dissolution of cobalt may result in the surface composition with cobalt depression or Pt (or Pd) enrichment. Little fundamental data of the composition and oxide film on the alloy for the ORR has reported.

In this study, Pt-Co and Pd-Co alloy electrodes with various Co concentration were investigated for the ORR in $0.5 \mathrm{M} \mathrm{H}_{2} \mathrm{SO}_{4}$, which is a model electrolyte in the PEFC cathode. The surface composition and the formation of surface oxide films were examined by using XPS (X-ray photoelectron spectroscopy) and GD-OES (glow discharge optical emission spectroscopy). The formation of oxides and their thickness on alloy surfaces were traced on the ORR potential range by in-situ ellipsometry and in-situ laser Raman scattering spectroscopy (17-19). The influence on the ORR current of the presence of surface oxide films and of the change in surface composition of the alloys have been electro- chemically investigated.

\section{Experimental}

Pd-Co and Pt-Co alloys were prepared by melt-mixing of Co (99.9\%) and Pt (99.9\%) or Pd (99.9\%) in Ar arc furnace to make disc-form electrode $1.5 \mathrm{~mm}$ thick at the given compositions in molar fraction. The alloy formation was examined by line analysis of EPMA. Their elemental compositions were determined by X-ray fluorescence analysis.

The ORR catalytic efficiency of the alloy electrodes was measured in $0.5 \mathrm{M}$ sulfuric acid under oxygen atmosphere. Prior to each experiment, the surfaces of alloy electrodes were polished to a mirror finish with $0.05 \mu \mathrm{m}$ almina powder and then ultrasonicly washed in acetone. The surface area of electrodes exposed was $0.50 \mathrm{~cm}^{2}$. The reference electrode of $\mathrm{Ag} / \mathrm{AgCl} /$ saturated $\mathrm{KCl}$ was used (0.20 V vs. SHE).

A rotating analyzer-type of ellipsometer was used at which the light source is He-Ne gas laser with $632.8 \mathrm{~nm}$ wave length and the incident angle is $60^{\circ}$ ( $\pi / 3$ radian). From the ellipsometry, relative ampritude ratio, $\tan \Psi$, and relative phase retardation, $\Delta$, and reflectance, $R$ was measured. From the three parameters, the three unknowns of $n_{2}$ (refractive index of the film), $k_{2}$ (extinction coefficient of the film), and the $d$ (thickness of the film) was calculated with the Fresnel's and Drude's equations. The ellipsometry was also used to optically detect the change of the alloy surfaces.

In-situ laser Raman scattering spectroscopy was used in order to identify the oxide on electrode surfaces. Ar gas laser with $514.5 \mathrm{~nm}$ wave length and $80 \mathrm{~mW}$ output power was used for excitation. The Raman scattering light was detected by CCD at the exposure time of 10 s and the integration of 100 times. The confocal optical system with a pinhole was designed in order to remove the Raman scattering light from surrounding sulfuric acid solution.

The elemental analysis of the electrode surfaces was carried out by using GD-OES in order to investigate the surface before and after cyclic voltammetries.

The alloy electrode surfaces was measured by XPS.

\section{Results}

\section{$\underline{\text { CVs of Pt-Co alloy electrodes }}$}

Fig. 1 shows voltammograms which was measured after 9 cycles of the cyclic voltammetry $(\mathrm{CV})$ at $10^{-2} \mathrm{Vs}^{-1}$ between $0.3-1.2 \mathrm{~V}$ (vs. $\mathrm{Ag} / \mathrm{AgCl} / \mathrm{sat} . \mathrm{KCl}$ ). In Fig. 1, the

thickness of surface oxide films measured by in-situ ellipsometry is also plotted for Pt- 60 
and 50 at.\%Co alloys and Pt electrode in $0.5 \mathrm{M}$ sulfuric acid solution during nitrogen atmosphere. The anodic current for the oxide formation of the metal is observed at the higher potential than $0.65 \mathrm{~V}$, and the cathodic current with the oxide reduction at the lower potential. The Pt- 60 at.\%Co alloy electrode shows the larger anodic and cathodic current than the alloy electrodes with the lower Co concentration. The Pt alloy electrodes with higher Co concentration than 60 at.\% showed the remarkable dissolution wave and introduced increase of surface roughness. For the all electrodes, the oxide thickness increases with increase of the anodic current to a range from 1.8 to $2.5 \mathrm{~nm}$. During the cathodic scan, the oxide film is reduced at potentials lower than $0.6 \mathrm{~V}$. It is seen that the Pt alloy electrodes have thicker oxides than that on pure Pt electrode. The oxides formed are thicker with increase of Co addition.

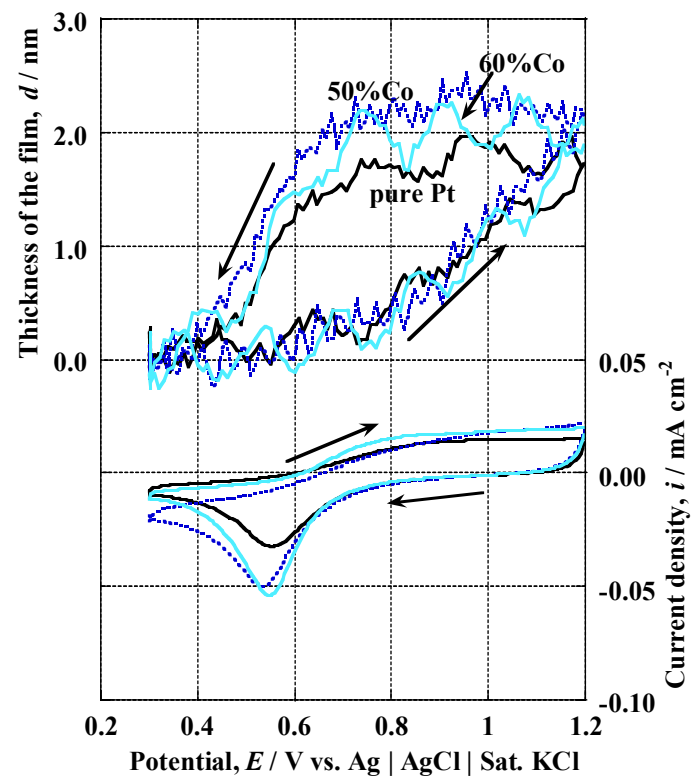

Fig. 1. Potential-current relation of Pt-Co alloy electrodes with different compositions in $0.5 \mathrm{M}$ sulfuric acid solution at a sweep rate of $10 \mathrm{mVs}^{-1}$. The relation was measured in the 10th cycle of $\mathrm{CV}$.

\section{$\underline{\text { CVs of Pd-Co alloy electrodes }}$}

Fig. 2 shows voltammograms which was measured after 9 cycles of the cyclic voltammetry $(\mathrm{CV})$ at $10^{-2} \mathrm{Vs}^{-1}$ between $0.3-1.2 \mathrm{~V}$. In Fig. 2, the thickness of the oxide is also plotted for Pd- 50 and 25 at.\%Co alloys and Pd electrode. As well as the Pt alloys, anodic and cathodic current appear with the formation of oxides and the reduction of oxides, respectively. The thicker oxide films can be formed on the Pd alloys than those on the Pt alloys. 


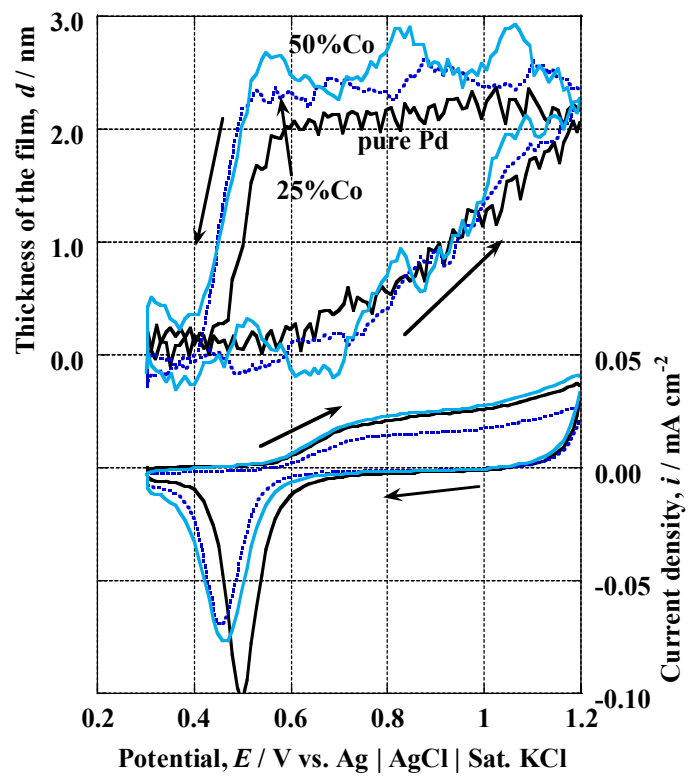

Fig. 2. Potential-current relation of Pd-Co alloy electrodes with different compositions in $0.5 \mathrm{M}$ sulfuric acid solution at a sweep rate of $10 \mathrm{mVs}^{-1}$. The relation was measured in the 10th cycle of CV.

\section{$\underline{\text { ORR current on the oxide covered electrodes }}$}

To investigate the influence on the overpotential of the oxide films formed on surface, Fig. 3 show the cathodic voltammograms for Pt- and Pd- 25 at.\%Co alloy electrodes at $10^{-3} \mathrm{Vs}-1$ in oxygen atmosphere after the oxidation at $1.2 \mathrm{~V}$ or $0.8 \mathrm{~V}$ for $1 \mathrm{~h}$. It is seen that the overpotential for the Pt alloy electrode previously oxidized at $1.2 \mathrm{~V}$ is larger about 0.1 $\mathrm{V}$ than that oxidized at $0.8 \mathrm{~V}$. The increase of the overpotential may be due to the oxide formation. From the ellipsometry, the thickness of the oxide oxidized at $1.2 \mathrm{~V}$ was found to be $2.0 \mathrm{~nm}$, and that at $0.8 \mathrm{~V}$ to be $0.2 \mathrm{~nm}$. The thickness difference may be reflected for the difference in the overpotential. If one compared between the Pd-Co alloy and PtCo alloy electrodes, the difference in overpotential between the electrode oxidized at 1.2 $\mathrm{V}$ and $0.8 \mathrm{~V}$ for the Pt-Co electrodes is larger than that for the Pd-Co electrodes.

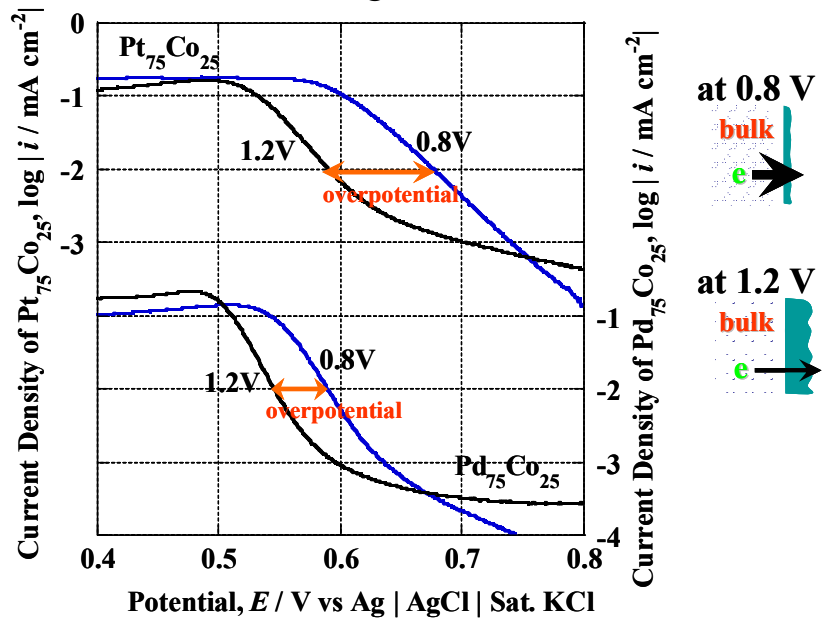

Fig. 3. Effect of the previous oxidation on ORR current in $0.5 \mathrm{M}$ sulfuric acid solution. The ORR current was measured on Pt- or Pd-75at.\%Co alloy electrode at a sweep rate of $10^{-3} \mathrm{Vs}^{-1}$ from $1.2 \mathrm{~V}$ or $0.8 \mathrm{~V}$ to $0.2 \mathrm{~V}$ after $1 \mathrm{~h}$ oxidation at $1.2 \mathrm{~V}$ or at $0.8 \mathrm{~V}$. 
ORR current of the oxide covered electrodes under constant potential control

Since the oxide still remain at $0.57 \mathrm{~V}$ on the electrodes previously oxidized at high potential, it is considered that the larger overpotential may be arisen. The ORR current on $\mathrm{Pt}$ and Pd alloy electrodes at $E=0.57 \mathrm{~V}$ is shown in Fig. 4 and Fig. 5 after $10^{-3} \mathrm{Vs}^{-1}$ cathodic sweep from 1.2 to $0.57 \mathrm{~V}$ following the oxidation of $1.2 \mathrm{~V}$ for $1 \mathrm{~h}$ in nitrogen atmosphere. Oxygen gas started to inserted at the time of $1800 \mathrm{~s}$ at $0.57 \mathrm{~V}$. The ORR current should be compared between the various compositions of the alloys. For both Pt and Pd alloys, the ORR current increase with Co addition. ORR current of Pd alloys tend to decay with time. This may be considered that their surface situations change with time; the growth of oxide film, the dissolution of $\mathrm{Co}$ and so on. Since the reduction of oxide begins near $0.57 \mathrm{~V}$, the reproducibility of their surface situations may be difficult to attain.

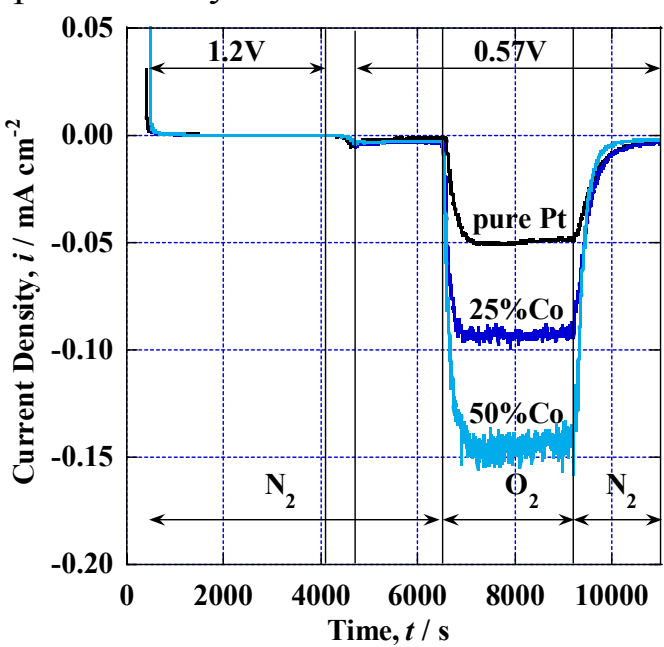

Fig. 4. ORR current density of Pt-Co alloy electrodes at potential of $0.57 \mathrm{~V}$ vs. $\mathrm{Ag} / \mathrm{AgCl} /$ sat. $\mathrm{KCl}$ in $0.5 \mathrm{M}$ sulfuric acid solution. The atmosphere was changed from $\mathrm{N}_{2}$ atmosphere to $\mathrm{O}_{2}$ bubbling after $1800 \mathrm{~s}$ at a constant potential of $0.57 \mathrm{~V}$, following the oxidation at $1.2 \mathrm{~V}$ for $1 \mathrm{~h}$ and the cathode sweep at $1 \mathrm{mVs}^{-1}$ of rate speed from $1.2 \mathrm{~V}$ to $0.57 \mathrm{~V}$ in $\mathrm{N}_{2}$ atmosphere.

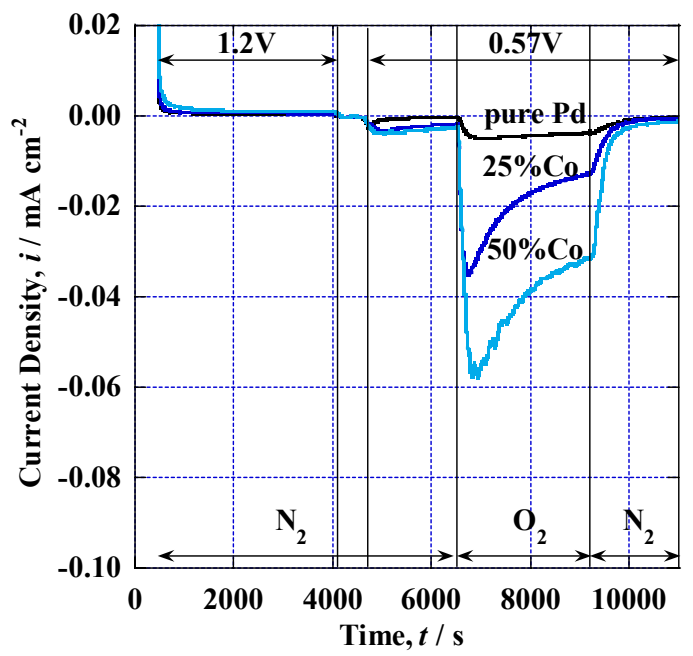

Fig. 5. ORR current density of Pd-Co alloy electrodes at potential of $0.57 \mathrm{~V} \mathrm{vs}$. Ag/ $\mathrm{AgCl} /$ sat. $\mathrm{KCl}$ in $0.5 \mathrm{M}$ sulfuric acid solution. The atmosphere was changed from $\mathrm{N}_{2}$ atmosphere to $\mathrm{O}_{2}$ bubbling after $1800 \mathrm{~s}$ at a constant potential of $0.57 \mathrm{~V}$, following the oxidation at $1.2 \mathrm{~V}$ for $1 \mathrm{~h}$ and the cathode sweep at $1 \mathrm{mVs}^{-1}$ of rate speed from $1.2 \mathrm{~V}$ to $0.57 \mathrm{~V}$ in $\mathrm{N}_{2}$ atmosphere. 


\section{Discussion}

\section{Oxide formation and reduction}

As compared Pd alloys in Fig. 2 with Pt alloys in Fig. 1, the potentials at which the oxide formation and the oxide reduction start shift to the slightly negative. The potentials also changes to the negative with the Co addition. Further, the thicker surface oxides are formed with increase of the Co addition. It is seen as well that the oxide thickness of $\mathrm{Pd}$ alloys is larger than that of Pt alloys. The increase of oxide thickness possibly has an increase of the overpotential for oxygen reduction reaction (ORR), i.e., it may introduce the lower ORR efficiency. The discussion of the increase of the overpotential by the increase of thickness is presented later.

Fig. 6 shows CVs during 10 cycles and the apparent thickness growth and reduction of oxide for Pd- 60 at.\%Co alloy electrode. As compared with the Pd alloy electrodes at the lower Co concentration than 60 at. $\%$, the Pd- 60 at.\%Co electrode exhibits one order larger current, which increases with increase of the cycle. These increases of current mean that the electrode surface undergoes the more corrosion. The thickness of the oxides on Pd-Co alloy electrodes with the lower Co concentration than 60 at.\% does not show such large increase. As compared to Pt- 60 at.\%Co in Fig. 1, it is found that the thickness increase for Pd- 60 at $\%$ Co is remarkable. The thickness of the oxide on the $\mathrm{Pt}$ alloy is small and constant, if the cycles are repeated. The refractive index of the oxide which was simultaneously calculated is in 1.4-1.5. Since this value is low, it is expected that the oxide film is much hydrated.

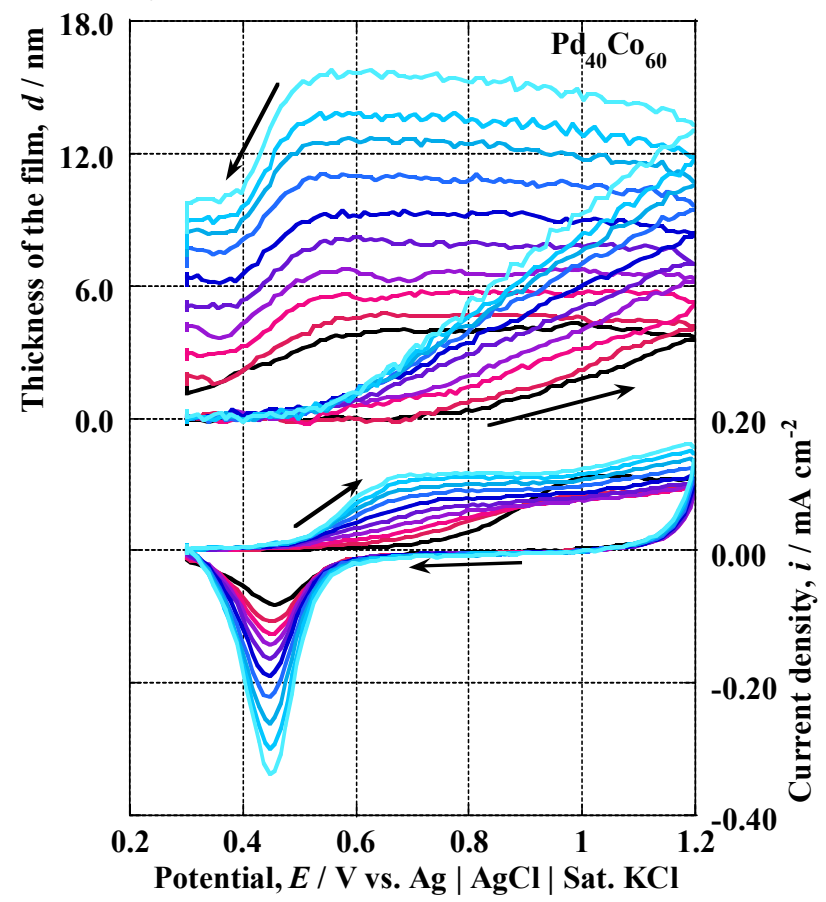

Fig. 6. Potential-current relation of Pd-40at.\%Co alloy electrode in $0.5 \mathrm{M}$ sulfuric acid solution during 10 cycles of $\mathrm{CV}$ at a sweep rate of $10 \mathrm{mVs}^{-1}$.

The remarkable increase of thickness during the continuing cycles may be explained as the following. During the anodic sweep, Co can be oxidized to Co(III) oxyhydroxide, $\mathrm{CoOOH}$. During the following cathodic sweep $\mathrm{CoOOH}$ is reductively dissolved to $\mathrm{Co}^{2+}$ in the electrolyte. With the cycles, the amount of $\mathrm{Co}^{2+}$ in the electrolyte increases. During 
the anodic sweep, the oxide film was formed from metallic $\mathrm{Co}$ as well as $\mathrm{Co}^{2+}$ ions in the electrolyte. The oxidative deposition from $\mathrm{Co}^{2+}$ may induce the thicker oxide film.

$$
\begin{aligned}
& \mathrm{Co}+2 \mathrm{H}_{2} \mathrm{O} \rightarrow \mathrm{CoOOH}+3 \mathrm{H}^{+}+3 \mathrm{e} \\
& \mathrm{Co}^{2+}+2 \mathrm{H}_{2} \mathrm{O} \rightleftarrows \mathrm{CoOOH}+3 \mathrm{H}^{+}+\mathrm{e}
\end{aligned}
$$

It is considered that Co depression layer is formed in the surface of the metal phase due to the dissolution of Co. According to GD-OES surface analysis, the Co depression layer of Pd- or Pt- 50 at.\%Co after CV measurements was estimated to be several hundred nm thick. For the $\mathrm{Pd}$ alloys lower than 50 at.\%Co, no remarkable increase of thickness during the continuing cycles appeared. The Co depression layer was also observed on Pt alloys as well as Pd alloys at every compositions by GD-OES. According to XPS, the Co oxide was found to be present in the outermost layer on Pt- or Pd- 50 at.\%Co after CV measurements. Raman scattering measurement revealed similar spectra as that of $\mathrm{CoOOH}$.

\section{Effect of oxide thickness on ORR current}

To investigate an influence of oxide outermost layer on the overpotential of ORR as shown in Fig. 3, the change of oxide film thickness with potential was measured by ellipsometry after the oxidation of $0.8 \mathrm{~V}$ or $1.2 \mathrm{~V}$. Fig. 7 and Fig. 8 show the ORR current and surface oxide thickness against potential for the Pt and Pd alloy electrodes, respectively, during cathodic sweep at $10^{-3} \mathrm{Vs}^{-1}$ after the oxidation of $1.2 \mathrm{~V}$ for $1 \mathrm{~h}$. The thickness of oxide was calculated with an assumption that the surface was free from the oxide at $0.3 \mathrm{~V}$.

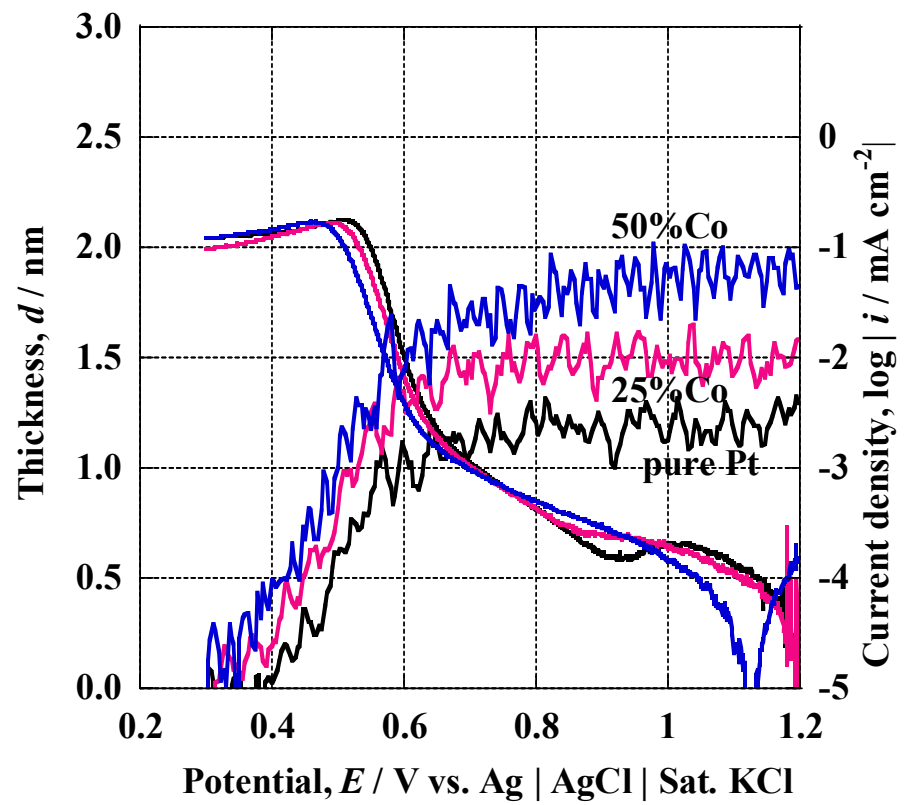

Fig. 7. Film thickness-potential and ORR current-potential relations on Pt-Co alloy electrodes with different compositions in $0.5 \mathrm{M}$ sulfuric acid solution. The electrodes were first oxidized at $1.2 \mathrm{~V}$ for $1 \mathrm{~h}$, then potential decreased to $0.2 \mathrm{~V}$ at a sweep rate of 1 $\mathrm{mVs}^{-1}$. 


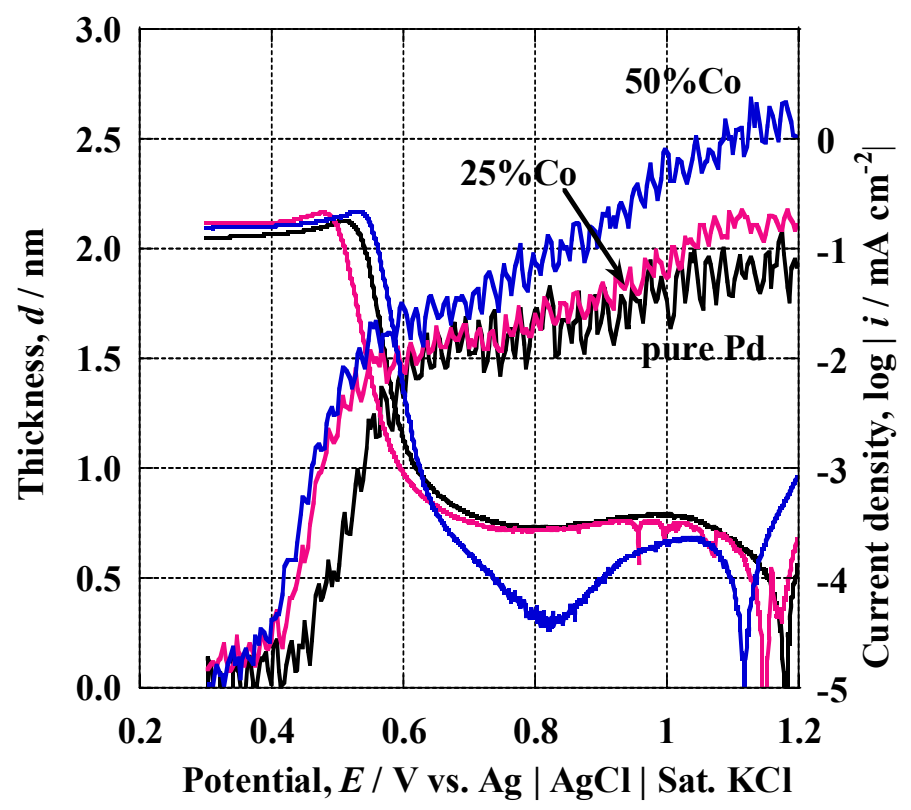

Fig. 8. Film thickness-potential and ORR current-potential relations on Pd-Co alloy electrodes with different compositions in $0.5 \mathrm{M}$ sulfuric acid solution. The electrodes were first oxidized at $1.2 \mathrm{~V}$ for $1 \mathrm{~h}$, then potential decreased to $0.2 \mathrm{~V}$ at a sweep rate of 1 $\mathrm{mVs}^{-1}$.

The thickness of the oxide film was not influenced by the difference in bubbling gas. Fig. 9 shows the reduction of the oxide film during the cathodic sweep in $\mathrm{N}_{2}$ and $\mathrm{O}_{2}$ atmosphere. Any difference of the film reduction is not seen between $\mathrm{N}_{2}$ and $\mathrm{O}_{2}$ atmosphere.

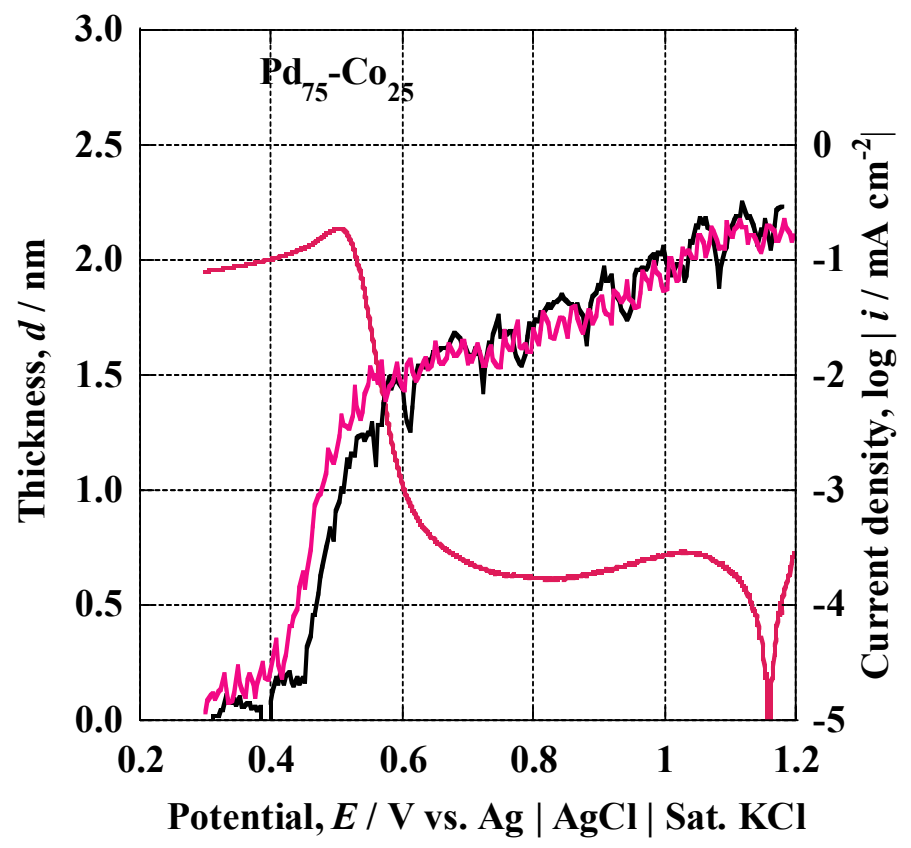

Fig. 9. Reduction of the oxide film as a function of potential in $\mathrm{N}_{2}$ or $\mathrm{O}_{2}$ atmosphere and ORR current density in $\mathrm{O}_{2}$ atmosphere on Pd-25at.\%Co alloy in $0.5 \mathrm{M}$ sulfuric acid solution. The electrodes were first oxidized at $1.2 \mathrm{~V}$ for $1 \mathrm{~h}$, then potential decreased to 0.2 $\mathrm{V}$ at a sweep rate of $1 \mathrm{mVs}^{-1}$. 
The thickness of oxide film at $1.2 \mathrm{~V}$ increases with increase of the Co addition for both Pt and Pd alloys. The oxide thickness on the Pt alloys is smaller than that on the Pd alloys, when compared at same Co concentration. The thickness of oxide film sharply decreases at around $0.6 \mathrm{~V}$. The ORR begins at around $0.65 \mathrm{~V}$ at which the oxide does not completely reduced. It is expected that the Pt and Pd alloys with the thicker oxide film may have the larger overpotential. Since the thicker oxides are formed o the alloys with the more concentration of $\mathrm{Co}$, the alloy electrodes with the more Co concentration would have the larger overvoltage. As shown in Fig. 4 and Fig. 5, however, it is seen that the ORR is accelerated by Co addition. It may be suggested that the overoptential do not only depend on the oxide thickness, but also on the amount of Co addition.

\section{Conclusion}

The ORR current was studied for Pt-Co and Pd-Co alloy electrodes on the surface composition and the formation of the surface oxide film.

(1) Pt-Co and Pd-Co alloy electrodes is covered by the oxide film in the potential in which ORR takes place. The thickness of the film on Pt-Co alloys was amounted to be 1-2 $\mathrm{nm}$ and that on Pd-Co alloys 2-3 nm.

(2) The overpotential for ORR is increased with the formation of the oxide film 2 $\mathrm{nm}$ thick by $0.09 \mathrm{~V}$ for Pt-Co alloys and by $0.04 \mathrm{~V}$ for the Pd-Co alloys.

(3) The addition of Co accelerate the ORR efficiency although the thickness of the oxide film increased with increase of Co addition.

(4) The depletion of Co is seen for both alloys and the depletion accelerates during the ORR due to the selective dissolution of Co.

(5) The alloys can be stably used at Co concentration lower than 65 at.\% for Pt-Co alloys and than 50 at.\% for Pd-Co alloys.

\section{Reference}

1. T. Toda, H. Igarashi, H. Uchida, and M. Watanabe, J. Electrochem. Soc., 146, 3750 (1999).

2. S. Mukerjee, S. Srinivasan, M. P. Soriaga, and J. McBreen, J. Electrochem. Soc., 142, 1409 (1995).

3. P. B. Balbuena, D. Altomare, L. Agapito, and J. M. Seminario, J. Phys. Chem. B, 107, 13671 (2003).

4. J. M. Seminario, L. A. Agapito, L. Yan, and P. B. Balbuena, Chem. Phys. Lett., 410, 275 (2005).

5. B. C. Beard and P. N. Ross Jr., J. Electrochem. Soc., 137, 3368 (1990).

6. U. A. Paulus, A. Wokaun, G. G. Scherer, T. J. Schmidt, V. Stamenkovic, N. M. Markovic, and P. N. Ross, J. Phys. Chem. B, 106, 4181 (2002).

7. H. A. Gasteiger, S. S. Kocha, B. Sompalli, and F. T. Wagner, Appl. Catal. B, 56, 9 (2005).

8. R. Pattabiraman, Appl. Catal. A, 153, 9 (1997).

9. K. Kinoshita, J. T. Lundquist, and P. Stonehart, J. Electroanal. Chem. Interfacial Electrochem., 48, 157 (1973).

10. Z. Gu and P. B. Balbuena, J. Phys. Chem. A, 110, 9783 (2006).

11. S. C. Zignani, E. Antolini, and E. R. Gonzalez, J. Power Sources, 182, 83 (2008).

12. W. E. Mustain, K. Kepler, and J. Prakash, Electrochim. Acta, 52, 2102 (2007). 
13. W. E. Mustain and J. Prakash, J. Power Sources, 170, 28 (2007).

14. K. Lee, O. Savadogo, A. Ishihara, S. Mitsushima, N. Kamiya, and K. -I. Ota, J. Electrochem. Soc., 153, A20 (2006).

15. O. Savadogo, K. Lee, K. Oishi, S. Mitsushima, N. Kamiya, and K. -I. Ota, Electrochem. Commun., 6, 105 (2004).

16. M. Pontinha, S. Faty, M. G. Walls, M. G. S. Ferreira, M. da Cunha Belo, Corr. sci., 48, 2971 (2006).

17. T. Ohtsuka and N. Sato, J. Electroanal. Chem., 147, 167 (1983).

18. N. Sato and T. Ohtsuka, J. Electrochem. Soc., 125, 1735 (1978).

19. T. Ohtsuka and N. Sato, J. Electrochem. Soc., 128, 2522 (1981). 